\title{
Monophasic action potential of right human atrium during atrial flutter and after conversion to sinus rhythm Argument for re-entry theory
}

\author{
S. Gavrilescu and S. Cotoi \\ From the First Medical Clinic, Institute of Medicine, Timisoara, Rumania
}

In 12 patients right atrial monophasic action potential recordings were obtained during atrial flutter and after conversion to sinus rhythm. Monophasic action potential duration is a valuable index of refractoriness of the atrial muscle; it ranges from 136 to 155 msec for the flutter waves and from 290 to $390 \mathrm{msec}$ for the regular sinus complexes. If the duration of the monophasic action potential of the flutter waves lengthens to about 200 msec sinus rhythm occurs; inversely, if sinus complexes present a monophasic action potential duration about 260-270 msec, flutter is impending. The results allow one to assume that the re-entry mechanism is one of the most important in the maintenance of atrial flutter. DC shock may be effective through depolarization of the atrial muscle, but it may have an additional effect on the refractoriness of the myocardium, allowing the slow depolarization of the re-entry pathway.

Intracardiac recording of monophasic action potential, using a suction electrode catheter (Korsgren et al., 1966; Shabetai, Surawicz, and Hamill, 1968; Olsson and Varnauskas, 1969; Olsson, 1970), offers new possibilities for obtaining information about the course of voltage time during activity of the atrial or ventricular muscle. Monophasic action potential recorded by such a method does not show the true transmembrane potential; nevertheless, it may be regarded as a close approximation to actual membrane variations (Hoffman and Cranefield, 1960; Suckling, 1961). Analysis of the monophasic action potential configuration in the intact human heart can give new insight about the basic mechanism of arrhythmias.

There are two principal theories for explaining the mechanism of atrial flutter. About 50 years ago, Lewis and collaborators (Lewis, 1918; Lewis, Feil, and Stroud, 1918; Lewis, Drury, and Iliescu, 192I) presented the 'circus movement' theory which implies the existence of a main excitatory wave of activation sweeping around the root of the vena cava and giving rise to secondary 'daughter' waves which spread over the other atrial territories. According to Katz and Pick (I953), atrial flutter is the outcome of a mulReceived 2 I June I97I. tiple re-entry mechanism following a definite pattern in most of the chamber. The second theory is the 'unifocal' one, presented by Rothberger (1922, I93I) and defended by Prinzmetal et al. (1952), Scherf, Schaffer, and Blumenfeld (1953), and Corday and Irving (I96I); it postulates the presence of a single ectopic focus of activation, giving off repetitive stimuli which reach all parts of both atria in a radical fashion.

Arguments for and against each of the above-mentioned theories have been forwarded, and various modifications of both have been suggested in order to explain the controversial data (Kisch, 1950; Rytand, I966).

The present paper describes the data obtained with the aid of monophasic action potential recordings in 12 patients with atrial flutter during this arrhythmia and after spontaneous or DC shock conversion to sinus rhythm.

\section{Technique and subjects}

We have used a monopolar suction electrode catheter which can be passed by the percutaneous way, at the bedside (Gavrilescu, Cotoi, and Pop, r972a, b). The catheter tip is placed under continuous monitoring in the right atrium, its bore is pushed gently against the endocardium, and negative pressure is applied with the aid of a simple 


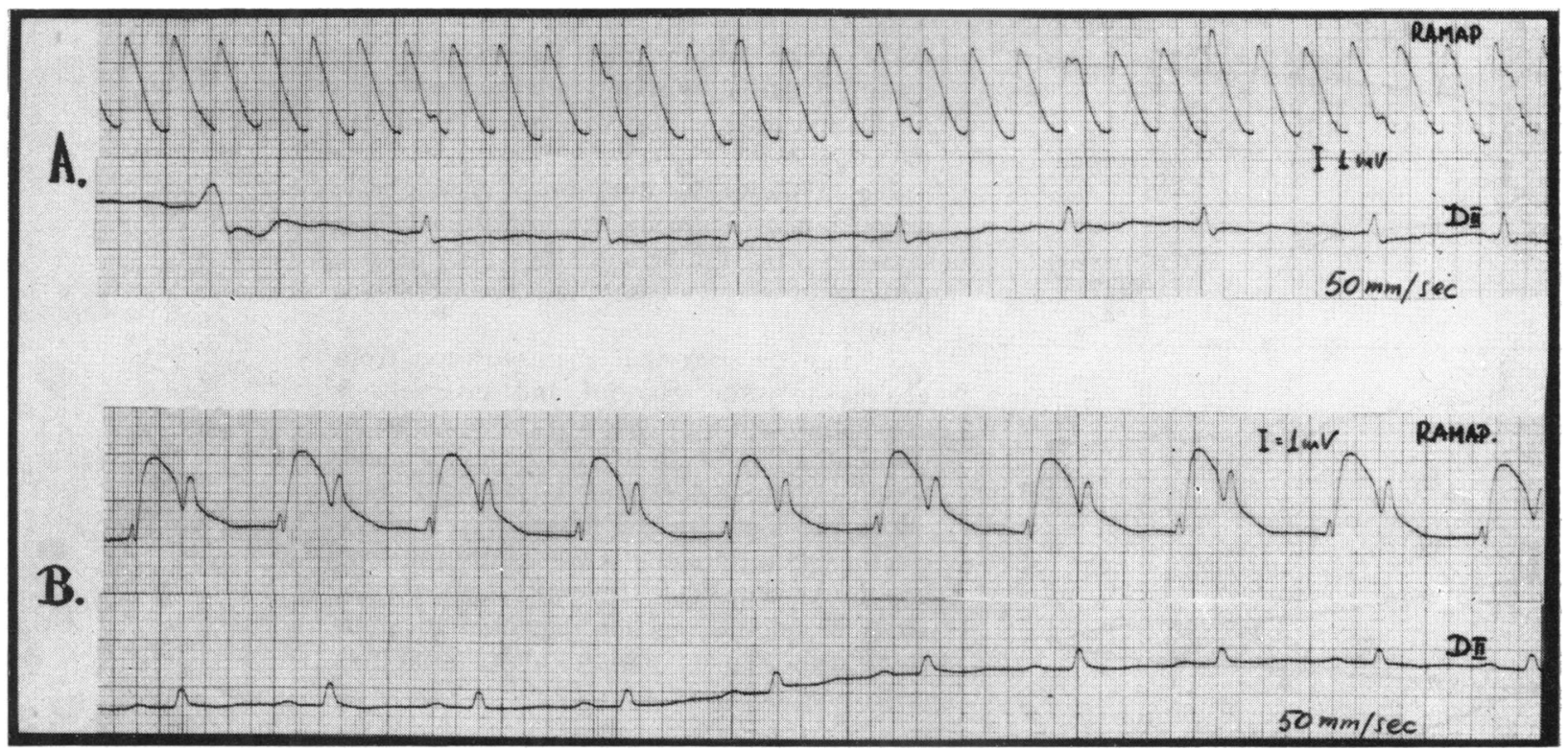

FIG. I Case 4. (A) Simultaneous recording of right atrial monophasic action potential and lead II, during atrial flutter $3 / 1$. The first beat is a ventricular premature beat. $(B)$ The same recording after conversion to sinus rhythm. The notch of the monophasic action potential tracing is an artefact due to the $Q R S$ complex.

suction device. Monophasic action potential can be recorded through the electrode catheter simultaneously with one or more standard electrocardiographic leads (Fig. I). Paper speed was 25,50 , or $100 \mathrm{~mm} / \mathrm{sec}$.

The monophasic action potential duration was measured on the baseline, from the beginning of phase $o$ till the end of phase 3. The monophasic action potential amplitude was measured from the baseline to the highest part of the curve. Mean value of 40 complexes was calculated for every patient (transition period not being included).

The right atrial monophasic action potential was recorded in 12 patients; the principal clinical data are shown in Table $\mathbf{I}$.

After recording the monophasic action potential of the flutter or fibrillatory waves in II patients, DC shock ${ }^{1}$ was applied in light narcosis. $^{2}$

In 7 instances atrial flutter occurred during attempt at cardioversion in cases with atrial fibrillation. Out of these, in 5 patients sinus rhythm occurred spontaneously some minutes - after the delivery of the DC shock and in 4 continuous recordings of the right atrial monophasic action potential (Fig. 2, 3, and 4). Several transitions from flutter to sinus rhythm were seen in 2 patients, before sinus rhythm occurred. In the

1 The DC shock was delivered with a Galileo defibrillator (OTE Italy), the shock was synchronized at approximately $0.20 \mathrm{sec}$ after the peak of the $R$ wave, and energies between $60-250 \mathrm{~W}$ sec were used.

${ }^{2} 5$ ethyl-5-(I-methyl-propyl)-2-thio-barbiturate. remaining 2 patients a second DC shock was necessary to abolish the ectopic rhythm.

In the other 5 patients atrial flutter was not preceded by any other arrhythmia. In one of them (Case 8) sinus rhythm occurred spontaneously.

After conversion to sinus rhythm, right atrial monophasic action potential was recorded again.

\section{Results}

Our findings are shown in Table 2 and Fig. 2-5.

The duration of the right atrial monophasic action potential during atrial flutter was from I36 to $155 \mathrm{msec}$ (mean value 148 ) for an atrial rate between 270 to 320 per minute (mean value 292). The amplitude of the right atrial monophasic action potential ranged from $2 \cdot 7$ to $4 \mathrm{mV}$ (mean value 3.5 ).

After conversion to sinus rhythm the duration of the right atrial monophasic action potential was between 290 and $390 \mathrm{msec}$ (mean value 327 ) and the amplitude ranged from 4.7 to $5.7 \mathrm{mV}$ (mean value 5.3 ).

There was a relation between the duration of the right atrial monophasic action potential in sinus rhythm and the recurrence of atrial fibrillation. All the patients with a right atrial monophasic action potential duration over 310 msec remained in sinus rhythm for more than 


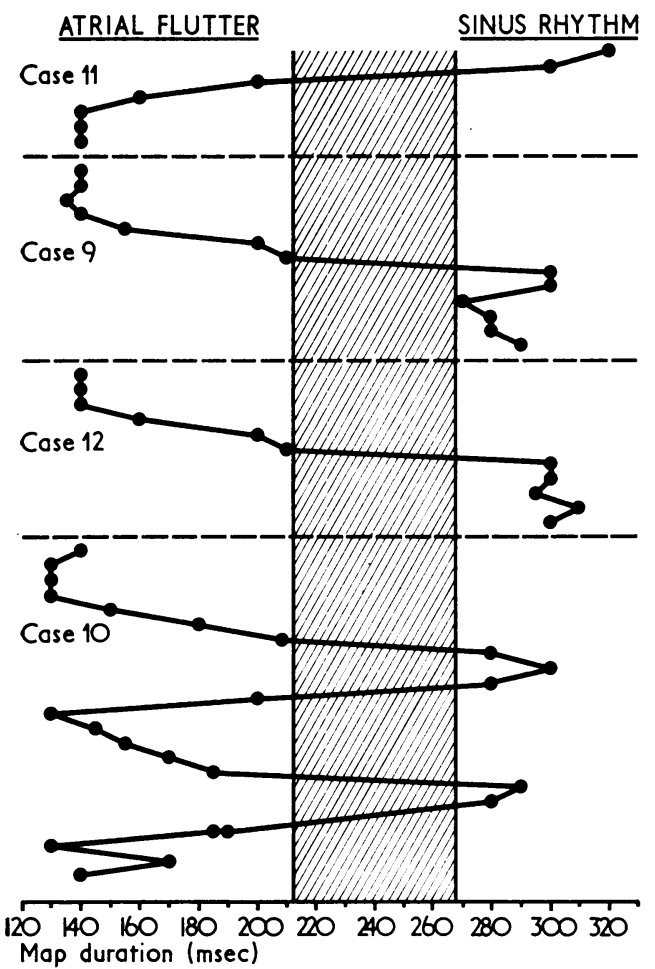

FIG. 2 Scheme of the transition period from atrial flutter to sinus rhythm in 4 patients (Cases II, 9, I2, and 10). The dots represent the duration of right atrial monophasic action potential of successive flutter waves and sinus complexes. The hatched area shows the threshold zone.
3 months while the 4 patients (Cases 3, 6, ro, and II) with a shorter right atrial monophasic action potential duration relapsed to atrial fibrillation after a period between $I$ and 28 days.

Fig. 2 shows the duration of monophasic action potential during the transition period between atrial flutter and sinus rhythm in 4 patients in whom a continuous recording was obtained.

It may be seen that the transition from ectopic to sinus rhythm and inversely is associated with a progressive prolongation or diminution, respectively, of the monophasic action potential duration. A threshold value about $200 \mathrm{msec}$ for the flutter waves monophasic action potential is constantly followed by sinus complexes. Inversely, when right atrial monophasic action potential in sinus rhythm shortens to $260-270 \mathrm{msec}$, atrial flutter is imminent.

\section{Discussion}

Right atrial monophasic action potential recorded by the suction technique is obtained from a great number of cells; therefore, it does not represent the true transmembrane potential. Nevertheless, its duration may be regarded as the expression of the refractoriness of the myocardium (Hoffman and Cranefield, 1960; Suckling, 196I). The refractory period of the cardiac muscle is an important determinant of the nature of response to a given stimulus.

TABLE I Principal clinical data of 12 patients

\begin{tabular}{|c|c|c|c|c|c|c|}
\hline $\begin{array}{l}\text { Case } \\
\text { No. }\end{array}$ & $\begin{array}{l}\text { Age } \\
(y r)\end{array}$ & Sex & Diagnosis & $\begin{array}{l}\text { Previous } \\
\text { duration } \\
\text { of flutter }\end{array}$ & Previous rhythm & $\begin{array}{l}\text { Modality of conversion to } \\
\text { sinus rhythm }\end{array}$ \\
\hline I & 50 & $M$ & Mitral valvular disease & $30 \mathrm{dy}$ & Sinus rhythm & DC shock \\
\hline 2 & 43 & $\mathrm{~F}$ & $\begin{array}{l}\text { Mitral stenosis; conges- } \\
\text { tive heart failure }\end{array}$ & $2 \mathrm{~min}$ & Atrial fibrillation & DC shock, transition period \\
\hline 3 & 48 & $\mathrm{~F}$ & Mitral stenosis & I $\min$ & Atrial fibrillation & DC shock \\
\hline 4 & 69 & $\mathbf{M}$ & Ischaemic heart disease & I4 dy & Sinus rhythm & DC shock \\
\hline 5 & 45 & $\mathrm{~F}$ & Mitral stenosis & $28 \mathrm{dy}$ & Sinus rhythm & DC shock \\
\hline 6 & 75 & $\mathbf{M}$ & $\begin{array}{l}\text { Ischaemic heart disease; } \\
\text { congestive heart failure }\end{array}$ & $21 \mathrm{dy}$ & Sinus rhythm & DC shock \\
\hline 7 & 70 & $\mathbf{M}$ & $\begin{array}{l}\text { Ischaemic heart disease; } \\
\text { congestive heart failure }\end{array}$ & $7 \mathrm{~min}$ & Atrial fibrillation & DC shock \\
\hline 8 & 58 & $\mathbf{M}$ & Mitral stenosis & I4 dy & Sinus rhythm & Spontaneously \\
\hline 9 & 62 & $\mathbf{F}$ & $\begin{array}{l}\text { Ischaemic heart disease; } \\
\text { congestive heart failure }\end{array}$ & Io $\mathrm{min}$ & Atrial fibrillation & DC shock, transition period \\
\hline 10 & 36 & $\mathbf{F}$ & $\begin{array}{l}\text { Mitral stenosis; conges- } \\
\text { tive heart disease }\end{array}$ & $2 \mathrm{~min}$ & Atrial fibrillation & $\begin{array}{l}\text { DC shock, multiple transition } \\
\text { periods }\end{array}$ \\
\hline I I & 60 & $\mathbf{F}$ & Ischaemic heart disease & $2 \mathrm{~min}$ & Atrial fibrillation & $\begin{array}{l}\text { DC shock, multiple transition } \\
\text { periods }\end{array}$ \\
\hline 12 & 62 & $\mathbf{M}$ & Ischaemic heart disease & $4 \mathrm{~min}$ & Atrial fibrillation & DC shock, transition period \\
\hline
\end{tabular}



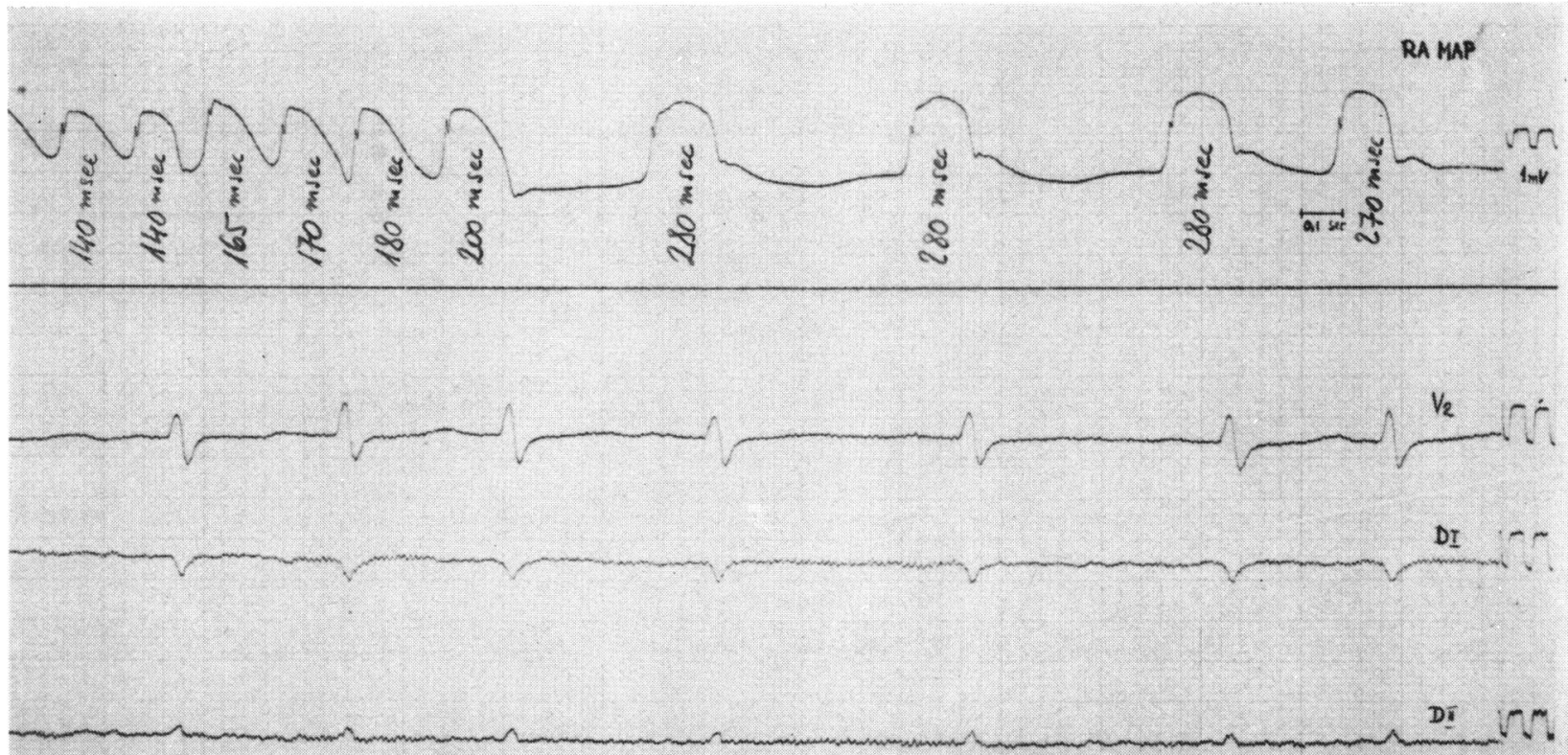

FIG. 3 Case 9. Simultaneous recording of right atrial monophasic action potential and 4

standard electrocardiogram leads during the transition period from atrial flutter to sinus rhythm, 3 minutes after the delivery of the DC shock. A progressive prolongation of the monophasic action potential of the flutter waves can be seen before sinus rhythm is reached. The last beat is a premature atrial beat. The duration in msec is shown below each monophasic action potential curve.

TABLE 2 Data obtained by right atrial monophasic action potential recording in the same patients as Table I

\begin{tabular}{|c|c|c|c|c|c|c|c|c|c|}
\hline \multirow[b]{2}{*}{$\begin{array}{l}\text { Case } \\
\text { No. }\end{array}$} & \multicolumn{5}{|c|}{ Atrial flutter } & \multicolumn{4}{|c|}{ Sinus rhythm } \\
\hline & $\begin{array}{l}\text { Atrial } \\
\text { rate }\end{array}$ & $\begin{array}{l}\text { Ventri- } \\
\text { cular } \\
\text { rate }\end{array}$ & $\begin{array}{l}\text { Monophasic } \\
\text { action poten- } \\
\text { tial duration } \\
(\mathrm{msec})\end{array}$ & $\begin{array}{l}\text { Monophasic } \\
\text { action poten- } \\
\text { tial amplitude } \\
(m V)\end{array}$ & Observations & $\begin{array}{l}\text { Heart } \\
\text { rate }\end{array}$ & $\begin{array}{l}\text { Monophasic } \\
\text { action poten- } \\
\text { tial duration } \\
(\mathrm{msec})\end{array}$ & $\begin{array}{l}\text { Monophasic } \\
\text { action poten- } \\
\text { tial amplitude } \\
(\mathrm{mV})\end{array}$ & $\begin{array}{l}\text { Heart rhythm } \\
\text { after } 3 \text { mth }\end{array}$ \\
\hline $\mathbf{I}$ & 280 & 140 & $149( \pm 5)$ & $3.8( \pm 0.5)$ & - & 85 & $352( \pm 3)$ & $5( \pm 0.4)$ & Sinus rhythm \\
\hline 2 & 272 & 136 & $154( \pm 12)$ & $3.7( \pm 0.7)$ & - & 72 & $315( \pm 8)$ & $4.9( \pm 0.4)$ & Sinus rhythm \\
\hline 3 & 300 & 150 & $152( \pm 9)$ & $4( \pm 0.5)$ & 一 & 86 & $300( \pm 5)$ & $5.1( \pm 0.5)$ & $\begin{array}{l}\text { Atrial fibrillation } \\
\text { after } 14 \mathrm{dy}\end{array}$ \\
\hline 4 & 270 & 120 & $152( \pm 7)$ & $3.2( \pm 0.9)$ & $\begin{array}{l}\text { Atrial flutter with varying } \\
\text { ventricular responses }\end{array}$ & 70 & $378( \pm 5)$ & $4.7( \pm 0.9)$ & Sinus rhythm \\
\hline 5 & 320 & 75 & $138( \pm 3)$ & $2 \cdot 7( \pm 0.7)$ & $\begin{array}{l}\text { Atrial flutter with varying } \\
\text { ventricular responses }\end{array}$ & 100 & $354( \pm 6)$ & $5 \cdot 2( \pm 0.4)$ & Sinus rhythm \\
\hline 6 & 310 & 70 & $136( \pm 8)$ & $3 \cdot 2( \pm 0 \cdot 9)$ & $\begin{array}{l}\text { Atrial flutter with varying } \\
\text { ventricular responses }\end{array}$ & 80 & $295( \pm 3)$ & $5.4( \pm 0.4)$ & $\begin{array}{l}\text { Atrial fibrillation } \\
\text { after I dy }\end{array}$ \\
\hline 7 & 290 & 68 & $152( \pm 5)$ & $3.2( \pm 0.5)$ & $\begin{array}{l}\text { Atrial flutter with varying } \\
\text { ventricular responses }\end{array}$ & 73 & $335( \pm 7)$ & $5.4( \pm 0.5)$ & Sinus rhythm \\
\hline 8 & - & - & 一 & 一 & 一 & 94 & $390( \pm 7)$ & $5.8( \pm 0.6)$ & Sinus rhythm \\
\hline 9 & $\begin{array}{l}300 \\
208\end{array}$ & $\begin{array}{l}150 \\
146\end{array}$ & $\begin{array}{l}150( \pm 4) \\
155( \pm 10)\end{array}$ & $\begin{array}{l}3.9( \pm 0.7) \\
3.9( \pm 0.8)\end{array}$ & - & $\begin{array}{l}90 \\
80\end{array}$ & $\begin{array}{l}310( \pm 4) \\
290( \pm 7)\end{array}$ & $\begin{array}{l}5.5( \pm 0.4) \\
5.1( \pm 0.6)\end{array}$ & $\begin{array}{l}\text { Sinus rhythm } \\
\text { Atrial fibrillation }\end{array}$ \\
\hline IO & 298 & 146 & $145( \pm 10)$ & $3.9( \pm 0.8)$ & 一 & 80 & $290( \pm 7)$ & $5 \cdot 1( \pm 0 \cdot 6)$ & $\begin{array}{l}\text { Atrial fibrillation } \\
\text { after } 21 \text { dy }\end{array}$ \\
\hline I I & 280 & 140 & $155( \pm 7)$ & $3 \cdot 1( \pm 0 \cdot 6)$ & 一 & 75 & $290( \pm 3)$ & $5.5( \pm 0.4)$ & $\begin{array}{l}\text { Atrial fibrillation } \\
\text { after } 28 \mathrm{dy}\end{array}$ \\
\hline 12 & 288 & 85 & $145( \pm 8)$ & $3 \cdot 8( \pm 0.3)$ & $\begin{array}{l}\text { Atrial flutter with varying } \\
\text { ventricular responses }\end{array}$ & 78 & $315( \pm 7)$ & $5 \cdot 7( \pm 0.5)$ & Sinus rhythm \\
\hline
\end{tabular}




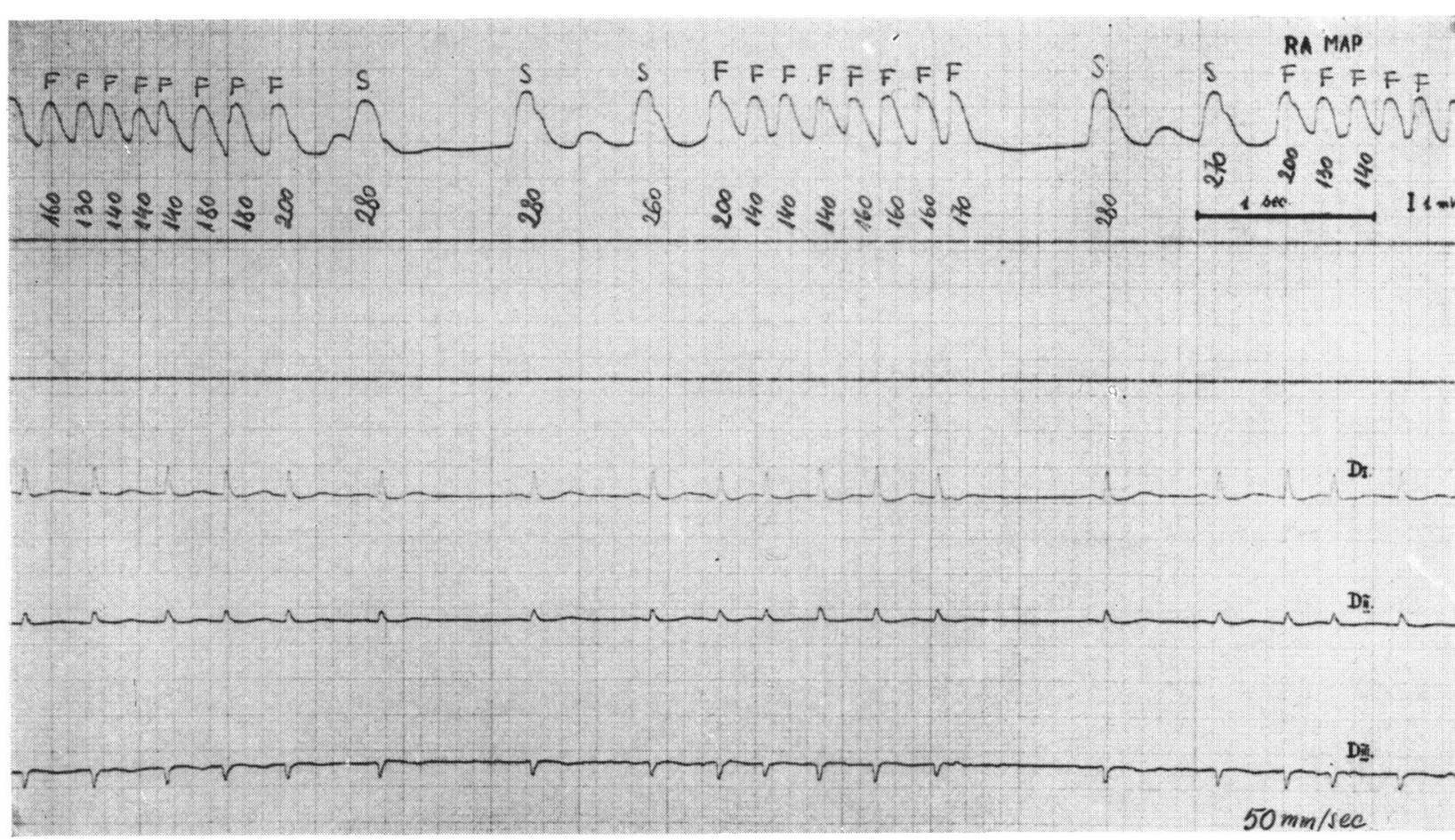

FIG. 4 Case IO. Simultaneous recording of right atrial monophasic action potential and 3 standard electrocardiogram leads, showing, a few minutes after DC shock, repeated transitions from atrial flutter to sinus rhythm and from sinus rhythm to flutter. Finally, sinus rhythm was established. Note the progressive prolongation of the monophasic action potential duration of the flutter waves $(F)$, as well as the shortening of the duration of monophasic action potential in sinus rhythm $(S)$ before the transition. The duration in msec is shown below each monophasic action potential curve. The twelfth and the twenty-second right atrial monophasic action potential complexes with a duration of $200 \mathrm{msec}$ are atrial premature beats initiating atrial flutter.

The progressive prolongation of the right atrial monophasic action potential duration of the flutter waves from $\mathrm{I} 48$ to $200 \mathrm{msec}$ is a constant finding in our cases in which the transition period to sinus rhythm was continuously recorded. It appears that the reentry mechanism may be interrupted by a prolongation of the refractory period. Inversely, re-entry can be favoured by a shortening of the refractoriness of the atrial muscle during sinus rhythm. In our cases progressive shortening of the right atrial monophasic action potential to about $260-270 \mathrm{msec}$ is followed by atrial flutter. It should be noted that shorter right atrial monophasic action potential, below $310 \mathrm{msec}$ after conversion to sinus rhythm, is associated with the recurrence of the ectopic mechanism.

In Fig. 6 different atrial arrhythmia is shown for comparison: a burst of six successive ectopic beats, preceded and followed by sinus rhythm. The atrial complexes show a constant duration of the monophasic action potential, demonstrating a rapid firing focus.

DC shock is the method of choice for conversion of atrial flutter to sinus rhythm (Lown, 1964; Bouvrain, Coumel, and Saumont, 1966). The efficacy of countershock is thought to be due to its ability to depolarize the whole atrium bringing all the elements into a phase favourable for resumption of organized activity. This assumption may be true for the patients in whom sinus rhythm immediately replaces atrial arrhythmia. In the cases in which the conversion takes place some minutes after the delivery of the shock and a progressive prolongation of the monophasic action potential of the flutter waves is present, the effect of DC shock can be explained by a critical lengthening of the refractory period which interrupts re-entry mechanism. 
FIG.5 Case II. Simultaneous recording of right atrial monophasic action potential and three standard electrocardiogram leads, during recurrence of flutter. The first three beats are sinus complexes $(S)$. Note the shortening of right atrial monophasic action potential duration before the onset of atrial flutter $(F)$ - with irregular ventricular response. The duration in msec is shown below the monophasic action potential curve. The patient reverted to sinus rhythm.

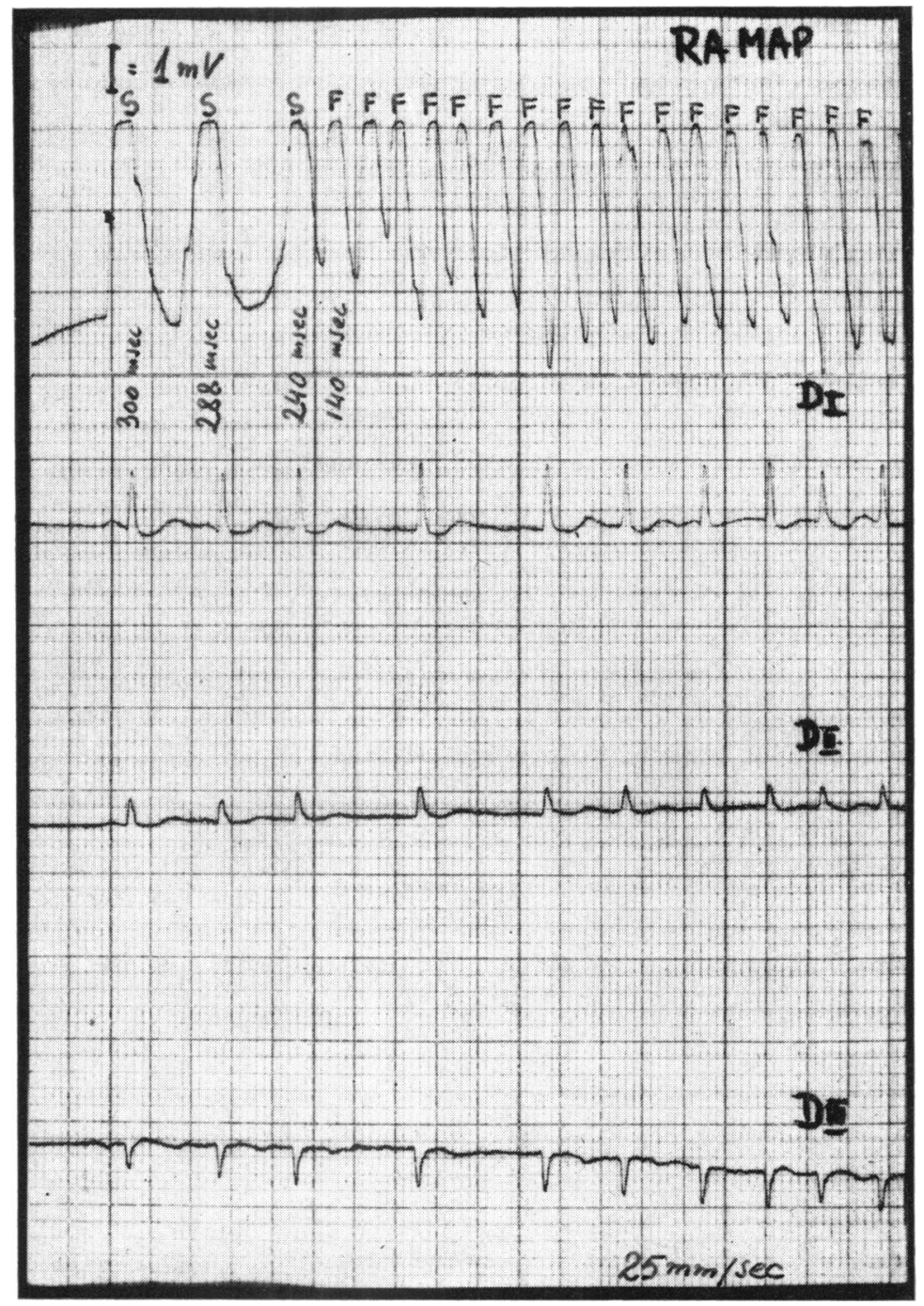

FIG. 6 Simultaneous recording of right atrial monophasic action potential and electrocardiogram lead 2, showing a burst of 6 successive atrial ectopic beats (arrows). The monophasic action potential duration of sinus rhythm complexes is 320 msec, while during ectopic ,rhythm it is 300 msec. The onset and the end of the ectopic activity take place without progressive change in the monophasic action potential duration.

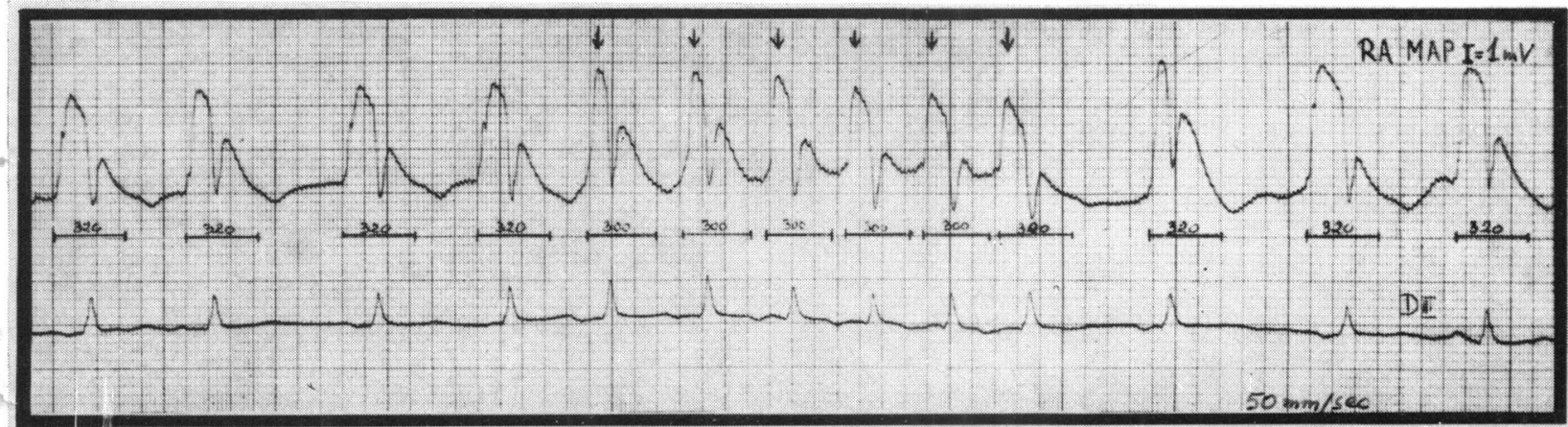




\section{References}

Bouvrain, Y., Coumel, Ph., and Saumont, R. (1966). Traitement du flutter auriculaire par les chocs électriques externes. Cardiologia, 49, I 22.

Corday, E., and Irving, D. W. (196I). Disturbances of Heart Rate Rhythm and Conduction. Saunders, Philadelphia and London.

Gavrilescu, S., Cotoi, S., and Pop, T. (1972a). The monophasic action potential of the right human atrium. A simple bedside suction technique and the first results in atrial arrhythmias. Cardiology. In the press.

Gavrilescu, S., Cotoi, S., and Pop, T. (1972b). L'enregistrement du potentiel monophasique d'action de l'auricule et du ventricule droite chez l'homme. Revue Roumaine de Médecine Interne. In the press.

Hoffman, B. F., and Cranefield, P. F. (1960). Electrophysiology of the Heart. McGraw-Hill, New York, Toronto, and London.

Katz, L. N., and Pick, A. (1953). The mechanism of auricular flutter and auricular fibrillation. Circulation, 7, 601.

Kisch, B. (1950). The mechanics of flutter and fibrillation. A short review of a century of studies. Cardiologia, 17, 244.

Korsgren, M., Leskinen, E., Sjöstrand, U., and Varnauskas, E. (1966). Intracardiac recording of monophasic action potentials in the human heart. Scandinavian fournal of Clinical and Laboratory Investigation, 18, 61.

Lewis, T. (1918). Observations upon flutter and fibrillation. IV, Impure flutter; theory of circus movement. Heart, 7, 293.

Lewis, T., Drury, A. N., and Iliescu, C. C. (I92I). Further observations upon the state of rapid reexcitation of the auricles. Heart, 8, $31 \mathrm{I}$.
Lewis, T., Feil, H. S., and Stroud, W. D. (1918). Observations upon flutter and fibrillation. II. The nature of auricular flutter. Heart, 7, 191 .

Lown, B. (1964). 'Cardioversion' of arrhythmias. Modern Concepts of Cardiovascular Disease, 33, 869.

Olsson, B. (1970). In vivo recordings of action potentials in man. In Symposium on Cardiac Arrhythmias, Elsinore, Denmark, p.37. Ed. by E. Sandoe, E. Flensted-Jensen, and K. H. Oleson. AB Astra, Södertälje, Sweden.

Olsson, B., and Varnauskas, E. (1969). Monophasic action potentials from intact human heart. Effect of different heart rates. Circulation, 39-40, Suppl. III, 157.

Prinzmetal, M., Corday, E., Brill, I. C., Oblath, R. W., and Kruger, H. E. (1952). The Auricular Arrhythmias. Charles C. Thomas, Springfield, Illinois.

Rothberger, C. J. (1922). Neue Theorien über Flimmern und Flattern. Klinische Wochenschrift, 1, 82.

Rothberger, C. J. (1931). Normale und pathologische Physiologie der Rhythmik und Koordination des Herzens. Ergebnisse der Physiologie, biologischen Chemie und experimentallen Pharmakologie, 32, 472.

Rytand, D. A. (1966). The circus movement (entrapped circuit wave) hypothesis and atrial flutter. Annals of Internal Medicine, 65, 125.

Scherf, D., Schaffer, A. I., and Blumenfeld, S. (1953). Mechanism of flutter and fibrillation. Archives of Internal Medicine, 91, 333.

Shabetai, R., Surawicz, B., and Hamill, W. (1968). Monophasic action potentials in man. Circulation, 38, 34I.

Suckling, F. E. (1961). Bioelectricity. McGraw-Hill, New York, Toronto, and London.

Requests for reprints to Professor S. Gavrilescu, I-st Medical Clinic, str. Gh. Dima 5, Timisoara, Rumania. 